\title{
Examining the Relationships between the TEAS’ Score, BSN Matriculation and NCLEX-RN Pass Rate
}

Cordelia Chinwe Nnedu* and Marilyn Stanford Davis

Department of Nursing, Tuskegee University, Tuskegee, AL 36088, USA

\section{Abstract}

Publication History:

Background: The purpose of this quantitative retrospective study was to investigate the possible predictors of success in completing the baccalaureate-nursing program at a Historical Black College and University (HBCU) and passing the NCLEX-RN licensure exam. We addressed the following research questions: Is there a significant relationship among preprogram TEAS scores, completing the BSN program and passing the NCLEX-RN licensure exam?

Methods: The data for this study were collected from student records maintained by the BSN program based on archival data, which are data taken from records collected by educators or educational institution. The categories of data collected included the TEAS' scores, graduation status on the BSN program and NCLEX$\mathrm{RN}$ exam status.

Results: Data indicated that the group that scored 80 and Above had a significantly higher percentage of students that received their BSN ( $\mathrm{n}=11,91.7 \%$ ), relative to the other 2 groups, $\mathrm{X}^{2}(2)=7.36, \mathrm{p}<.05$. Study participants that scores 60-79 on the TEAS did not differ at a statistically significant level from the reference group (those that scored less than 60) in terms of likelihood of receiving or not receiving a BSN.

Conclusion: These findings show a consistent link between TEAS performance and academic success in a baccalaureate-nursing program and passing the NCLEX-RN licensure examination on first attempt.

\section{Introduction}

This study was based on four current trends that are affecting nursing educations, professional nursing practice and health care delivery at the national, regional and local levels. These are: (1) changes in population demographics (2) health care disparities among minorities and ethnic groups, (3) the need to enhance health care delivery to a culturally diverse society, and (4) graying of the current nursing workforce. The nursing shortage currently affecting the United States has challenged schools/colleges of nursing to educate nurses at a faster pace to meet the rising demand for health care according to the American Association of Colleges of Nursing [1]. The United States is projected to experience a shortage of RNs that is expected to intensify as Baby Boomers age and the need for health care grows [2]. According to the Bureau of Labor Statistics' Employment Projections 2014-2024, Registered Nurses (RN) is listed among the top occupations in terms of job growth through 2024, an increase of 439,300 or $16 \%$ [3]. The Bureau also projects the need for 649,100 replacement nurses in the workforce bringing the total number of job openings for nurses due to growth and replacements to 1.09 million by 2024 (https://www.bls.gov/opub/mlr/2015/article/ occupation-employment-projections-to-2024.htm).

Most studies pertaining to predictors related to TEAS were not found. Little empirical data exist regarding matriculation in a Bachelor of Science (BSN) nursing program and the ability to predict success on the NCLEX-RN exam using the TEAS score. On a qualitative study conducted by Nnedu [4], data suggested that both academic and non-academic variables can contribute to one's performance on the NCLEX-RN examination. In this study, the factors were explored that may influence the progression of nursing students and nurse educators need to determine the possible predictors for successfully completing the BSN nursing program at a 4-year institution located in the south-eastern United States and passing the NCLEX-RN licensure exam.

\section{The Problem}

According to the "United States RN workforce report card and shortage forecast" published in the January 2012 issue of the American Journal of Medical Quality, a shortage of registered nurses is projected to spread across the country between 2009 and 2030 [5]. The shortage is projected to intensify in the South and the West.

In October 2010, the Institute of Medicine (IOM) released its landmark report on The Future of Nursing, initiated by the Robert Wood Johnson Foundation, which called for increasing the number of baccalaureate-prepared nurses in the workforce to $80 \%$ and doubling the population of nurses with doctoral degrees. The current nursing workforce falls far short of these recommendations with only $55 \%$ of registered nurses prepared at the baccalaureate or graduate degree level [2].

A lot of money is involved in achieving college degrees especially for professional degrees. Meeting the admission requirement for baccalaureate nursing program is important and remaining in the program to graduation and subsequently passing the National Council Licensure Examination for Registered Nurses (NCLEX$\mathrm{RN}$ ) examination is important for students, faculty and nursing program. AACN reported a $3.6 \%$ enrollment increase in entry-level baccalaureate programs in nursing in 2016; they stated that this increase is not sufficient to meet the projected demand for nursing services, including the need for more nurse faculty, researchers, and primary care providers [2].

"Corresponding Author: Prof. Cordelia Chinwe Nnedu, Department of Nursing Tuskegee University, Tuskegee, AL 36088, USA; Tel: (334) 727-8185, Fax: (334) 727-5461; E-mail: cnnedu@tuskegee.edu

Citation: Nnedu CC, Davis MS (2018) Examining the Relationships between the TEAS' Score, BSN Matriculation and NCLEX-RN Pass Rate. Int J Nurs Clin Pract 6 : 304. doi: https://doi.org/10.15344/2394-4978/2019/304

Copyright: (C) 2018 Nnedu et al. This is an open-access article distributed under the terms of the Creative Commons Attribution License, which permits unrestricted use, distribution, and reproduction in any medium, provided the original author and source are credited. 
According to report from the Sullivan Commission [6] -the nation's health professions have not kept pace with changing demographics may be an even greater cause of disparities in health access and outcomes than the persistent lack of health insurance. Today's nurses have too little resemblance to the diverse populations they serve, leaving many Americans feeling excluded by a system that seems distant and uncaring (Missing Persons: Minority in the Health Professions).

The current nursing workforce does not reflect the ethnic and cultural diversity of rural and underserved communities in the United States. According to a 2013 survey conducted by the National Council of State Boards of Nursing (NCSBN) and The Forum of State Nursing workforce centers, nurses from minority backgrounds represent only19 percent of the registered Nurse (RN) workforce [7]. A 2015 National Center for Health Workforce Analysis (NCHWA) report titled Sex, Race, and ethnic Diversity of U. S. Health Occupations shows that only 20 percent of RNs are from racial/ethnic minority groups with 15 percent being from underrepresented populations. The study by Bednarz, Schim and Doorenbos [8] suggested that a diverse health care workforce is necessary to meet the needs of a diverse population and achieve population health equity. Nursing leaders recognize a strong connection between a culturally diverse nursing workforce and the ability to provide quality, culturally competent patient care. Though nursing has made great strides in recruiting and graduating nurses that mirror the patient population, more must be done before adequate representation becomes a reality.

\section{The Department of Nursing}

Our Nursing Program was established in 1892 to educate young black men and women who wanted to learn the art of caring for the sick. It is the oldest baccalaureate-nursing program in our state and one of the oldest predominantly black schools of nursing in continuous operation in the United States. The nursing program is accredited by the Accreditation Commission for Education in Nursing (ACEN) Students are admitted to the professional phase of the program in the summer and fall Semesters respectively. The nursing student body is 99.9 percent African American. Our goal is to be one the mechanisms for increasing minorities in the health professions and we want to do it right. . Diversity is a key to excellence in health care. To achieve that new vision, care must be provided by a well trained, qualified, and culturally competent health professions workforce that mirrors the diversity of the population it serves [6]. The numbers of elderly minorities are expected to grow to 22 percent of the elderly population in the next 20 years. The number of elderly minorities is projected to jump 226 percent, with Hispanics and Asian American and Pacific Islander population experiencing the highest growth [9]. If the theory that people respond better when being served by "someone who looks like them", the need for recruiting and graduating ethnic minority students cannot be overemphasized.

\section{Healthy People 2020}

One of the goals of Healthy People 2020 is to increase the proportion of baccalaureate degrees in the health professions awarded to members of underrepresented racial/ethnic minorities [9]. To accomplish this goal, more minority students must first be recruited and retained in the health professions. Additionally, minority nurses with baccalaureate degrees are needed because minority nurses tend to return to their community and improve access to health delivery systems for other minorities. Healthy People 2020 seek to increase life expectancy and quality of life...by helping individuals gain the knowledge, motivation, and opportunities they need to make informed decisions about their health.

The registered nurse (RN) workforce is one of the top ten occupations in the United States with an expected job growth of $26 \%$, which is an increase of 1.2 million nursing jobs through 2020 [10]. Nursing is a vocation and students admitted to clinical phase of the nursing program aspire to become RNs following the successful completion of the nursing courses and passing the NCLEX-RN examination. The schools/colleges of nursing face potential program closure from the State Board of Nursing when NCLEX-RN results for first time writers fall below acceptable score. Already graduation rate for BSN programs are less than $50 \%$ nationwide, even though the National League for Nursing Accrediting Commission (NLNAC) recommends that an acceptable retention rate is $80 \%$ [11].

\section{The Purpose}

The purpose of this quantitative retrospective study was to investigate the possible predictors of success in completing the baccalaureate-nursing program at a Historical Black College and University (HBCU) and passing the NCLEX-RN licensure exam. We addressed the following research questions: Is there a significant relationship among preprogram TEAS scores, completing the BSN program and passing the NCLEX-RN licensure exam?

\section{Sample}

The sample for this study includes a convenience sample of BSN nursing students from six graduating classes of May 2016, July 2016, May 2017, July 2018, May 2018 and July 2018, which were admitted in the summer 2014 through fall 2016. We have two admissions each year, summer and fall respectively. The sample for the study included all the students admitted to the BSN program in 2014 and 2016, which were 97 students. One-third of the students applied to the professional phase of nursing were not admitted because of not meeting the admission criteria and/or lack of faculty. The sample was mostly female, African American and composed of traditional college age students of 22 or younger. The setting for this study was a baccalaureate (BSN) program at a private university in the southeastern part of the United States.

\section{Data Collection}

The data for this study were collected from student records maintained by the BSN program based on archival data, which are data taken from records collected by educators or educational institution. The Test of Essential Academic Skills is administered by ATI, a nursing education company based in Kansas. Candidates are tested on subjects they will have learned during high school. It is actually a test of basic knowledge (as the name implies) in science, reading, English and math. The test was designed to predict which candidates are more likely to succeed in nursing school. There are 170 multiple choice questions. Time limit is 209 minutes. No calculators are allowed. The school has used the TEAS' score as one of the requirement for admission to the professional phase of the nursing curriculum. The investigators seek to look at data from six cohort group, from 2014 through 2016. Ninety-seven enrolled students met the criteria for inclusion on this study. The categories of data collected included the TEAS' scores, graduation status on the BSN program and NCLEX-RN exam status. 
Citation: Nnedu CC, Davis MS (2018) Examining the Relationships between the TEAS' Score, BSN Matriculation and NCLEX-RN Pass Rate. Int J Nurs Clin Pract 6: 304. doi: https://doi.org/10.15344/2394-4978/2019/304

\begin{tabular}{|l|l|c|c|c|c|c|c|}
\hline & & \multicolumn{2}{|c|}{ Received BSN } & \multicolumn{2}{c|}{ No-BSN } & & \\
\hline Variable & & $\mathrm{N}$ & $\%$ & $\mathrm{~N}$ & $\%$ & $\mathrm{X}^{2}(\mathrm{df})$ & $\mathrm{p}$ \\
\hline Teas Scores & & & & & & $7.36(2)$ & .03 \\
\hline & 80 and Above & 11 & 91.7 & 1 & 8.3 & & \\
\hline & $60-79$ & 22 & 53.7 & 19 & 46.3 & & \\
\hline & Less than 60 & 14 & 46.7 & 16 & 53.3 & & \\
\hline
\end{tabular}

Table 1: Chi-Square Analysis Examining Teas Scores By Educational Outcome (BSN vs. No-BSN) $(n=83)$.

\begin{tabular}{|l|l|l|l|l|}
\hline TEAS Scores & B (SE) & Wald (df) & OR (95\% CI) & $\mathrm{p}$ \\
\hline Less than 60 (Reference Group) & & & & \\
\hline 80 and Above & $2.53(1.11)$ & $5.23(1)$ & $12.57(1.43-110.01)$ & .02 \\
\hline $60-79$ & $.28(.48)$ & $.34(1)$ & $1.32(.52-3.40)$ & .56 \\
\hline
\end{tabular}

Table 2: Binary Logistic Regression Examining the Likelihood Of Receiving A BSN Vs. No-BSN Relative To TEAS Scores $(n=83)$.

For Overall Model: $\mathrm{X}^{2}(2)=8.64, \mathrm{p}<.05$.

The graduation status of the students was coded as 1 for completing the program, and coded as 2 for those who did not complete the program. The NCLEX-RN was coded as 1 for passed, 0 for failed and 3 for has not taken the test. The result of this study will be part of the school's program evaluation. The TEAS score were coded as follows: 1 for scores 80 and above, 2 for scores $60-79$ and 3 for scores less than 60 .

\section{Result}

Table 1 presents a chi-square analysis examining Teas scores by educational outcome (BSN vs. No-BSN). Data indicated that the group that scored 80 and Above had a significantly higher percentage of students that received their BSN $(n=11,91.7 \%)$, relative to the other 2 groups, $\mathrm{X}^{2}(2)=7.36, \mathrm{p}<.05$.

Table 2 presents a binary logistic regression examining the likelihood of receiving a BSN vs. No-BSN relative to TEAS scores. Analysis indicated that the overall regression model was statistically significant, $\mathrm{X}^{2}(2)=8.64, \mathrm{p}<.05$. Furthermore, study participants that scores 80 and above on the TEAS were over 12 times more likely $(\mathrm{OR}=12.57,95 \% \mathrm{CI}=1.43-110.01)$ than those that scored 60 and below to receive their $\mathrm{BSN}, \mathrm{B}=2.53, \mathrm{SE}=1.11$, Wald $=5.23, \mathrm{p}<.05$. Study participants that scores 60-79 on the TEAS did not differ at a statistically significant level from the reference group (those that scored less than 60) in terms of likelihood of receiving or not receiving a BSN.

Our NCLEX-RN pass rate has been above the national average. Of all data reviewed, only three students from the cohort used in this study did not pass the NCLEX-RN on first attempt.

\section{Limitations}

The study is limited to a BSN program located in the Deep South, as opposed to representative regions of the country. This particular BSN is not ethnically diverse and comprises of 99.9 percent African Americans. Therefore, the results of this study cannot be generalized to other schools of nursing. The findings of this study are reflective of the unique population of our nursing students, which does not reflect the population within the state or at other colleges.

\section{Conclusion}

These findings show a consistent link between TEAS performance and academic success in a baccalaureate-nursing program and passing the NCLEX-RN licensure examination on first attempt. The School has consistently achieved a high NCLEX-RN pass rate as shown on table 3. As stated in the Elkins [10] study, further studies on admission criteria and standardized testing would help nurse educators identify nursing applicants most likely to succeed in the program and passing the NCLEX-RN licensure exam, thus ensuring a competent nursing workforce and help to meet the nursing shortage in the future. In addition, one question remains, could those students who were not admitted in the nursing program be successful in matriculating through the nursing program? These investigators do not have the answer.

\begin{tabular}{|l|l|c|c|c|c|}
\hline \multicolumn{2}{|c|}{ NCLEX-RN Pass Rate } \\
\hline \multicolumn{2}{|c|}{} & Frequency & Percent & $\begin{array}{c}\text { Valid } \\
\text { Percent }\end{array}$ & $\begin{array}{c}\text { Cumulative } \\
\text { Percent }\end{array}$ \\
\hline \multirow{2}{*}{ Valid } & Pass & 52 & 53.6 & 94.5 & 94.5 \\
\cline { 2 - 6 } & Fail & 3 & 3.1 & 5.5 & 100.0 \\
\cline { 2 - 6 } & Total & 55 & 56.7 & 100.0 & \\
\hline Missing & System & 42 & 43.3 & & \\
\hline Total & & 97 & 100.0 & & \\
\hline
\end{tabular}

Table 3: This shows that of the fifty-five (55) students who have taken the NCLEX-RN examination, fifty-two of those were successful, which is a $94.5 \%$ for this cohort. The missing candidates are either still in the program in good standing or have not taken the NCLEXRN test.

\section{Author Contributions}

Dr. Cordelia C. Nnedu was responsible in the conception, design, analysis, interpretation of data and drafting the manuscript.

Dr. Marilyn Stanford Davis was responsible for the acquisition of data, proof reading the manuscript, and participated in the analysis of data.

\section{Competing Interests}

The authors declare that they have no competing interests. 
Citation: Nnedu CC, Davis MS (2018) Examining the Relationships between the TEAS’ Score, BSN Matriculation and NCLEX-RN Pass Rate. Int J Nurs Clin Pract 6: 304. doi: https://doi.org/10.15344/2394-4978/2019/304

\section{References}

1. American Association of Colleges of Nursing [AACN] (2017) Nursing Shortage.

2. American Association of Colleges of Nursing [AACN] (2018) Nursing Fact Sheets.

3. Bureau of Labor Statistics (2012) The 30 Occupations with the Largest Projected Employment Growth 2010-2020.

4. Nnedu CC (2000) Academic predictors of success for baccalaureate students on the national council Registered Nurse Licensure. Unpublished doctora dissertation, Auburn University, Auburn, Alabama.

5. Juraschek SP, Ranganathan V, Lin VW (2012) United States registered nurse workforce report card and shortage forecase. Am J Med Qual 27 214-219. Sullivan, Louis W (2004) Missing Persons: Minorities in the Health Professions, A Report of the Sullivan Commission on Diversity in the Healthcare Workforce.

6. National Council State Board of Nursing (2013) 2013 Annual Report

7. Bednarz H, Schim S, Doorenbos A (2010) Cultural diversity in nursing education: perils, pitfalls, and pearls. J Nurs Educ 49: 253-260.

8. Department of Health and Human Services (2013).

9. Elkins N (2015) Predictors of Retention and Passing the National Council Licensure Examination for Registered Nurses. Open Journal of Nursing 5 : 218-225

10. Brown J, Marshall BL (2008) A Historically Black University's Baccalaureate Universities Enrollment and Success Tactics for Registered Nurses. Journal of Professional Nursing 24: 21-29. 